\title{
Geografía, literatura e ideología en la segunda mitad del siglo XX: las "Guías de España” de Ediciones Destino
}

\section{Geography, literature and ideology in the second half of the 20th century: Spain Guides, Destino Publishers}

\author{
Fernando Arroyo Ilera ${ }^{\star}$
}

La editorial catalana Destino publicó, entre 1943 y 1977, un total de dieciséis guías de diversas regiones y ciudades de España que constituyen un importante legado editorial y literario de la época, a la vez que un inestimable documento para conocer una etapa crucial de la historia y la geografía de nuestro país. Este proyecto, al que el tiempo va confiriendo toda su dimensión cultural, es el pretexto que nos permite acercarnos a una forma de hacer geografía diferente a la convencional científica y académica, pero de creciente interés desde la perspectiva cultural de nuestra disciplina. Sobre todo, teniendo en cuenta que dicho proyecto no fue único en su época, aunque sí el más representativo de los varios del mismo tipo que se produjeron en esos años, ya fuera por imitación del mencionado o como consecuencia de las necesidades de la época.

Las guías de viaje o para le viajero constituyen un género geográfico menor, pero de larga tradición en nuestra disciplina, utilizadas muchas veces como fuentes de información sobre el territorio y algunas otras en sí mismas, como objeto directo de investigación geográfica, como es este caso. Al igual que su "hermano mayor", los libros de viajes, tienen en éste su razón originaria y su pretexto final. El viaje es una actividad fundamental de nuestra especie y de nuestra cultura, un auténtico hecho de civilización, con diferente carácter y personalidad según la época y sus protagonistas. Es una de

\footnotetext{
* Universidad Autónoma de Madrid. fernando.arroyo@uam.es
} 
las principales fuentes de conocimiento social, científico, artístico y literario y lo ha sido más en el pasado, cuando no se disponía de los medios de comunicación instantánea de nuestro tiempo. Se viaja por muchos motivos: por placer, por necesidad, para conocer un territorio, para educarse y frecuentemente, y esto es lo que ahora más nos interesa, para contar el viaje, lo viajado y el contexto en el que ambos se han producido.

Se puede relatar el viaje en cuanto tal, su historia y vicisitudes, en cuyo caso las tierras visitadas no son más que el contexto que acompaña a la acción. Por notables e interesantes que éstas puedan ser, lo principal es el argumento del viaje, en el que puede mezclarse la realidad con la ficción, tal como ocurre, sin ir más lejos, en la más universal de nuestras novelas. Pero en otras ocasiones, el viaje tiene como finalidad conocer y describir tierras, países y lugares, y aunque la personalidad del viajero y las circunstancias del periplo están siempre presentes, el auténtico sujeto del mismo es el territorio visitado y los paisajes y lugares según los descubren los protagonistas.

A lo largo de la historia podemos encontrar un rico muestrario de ejemplos de ambos tipos, incluso numerosos casos intermedios que configuran todo un estilo literario y un rico filón de información geográfica: exploradores, descubridores, embajadores, etc. aristócratas o simples aventureros, misioneros o militares, la relación de personas que ha sentido el irresistible deseo del viaje y la no menos evitable de relatar sus experiencias es interminable y, como es sabido, constituyen un aspecto esencial de nuestra disciplina.

\section{LAS GUÍAS PARA EL VIAJERO: TURISMO Y GEOGRAFÍA}

Otra cosa son las guías de viaje, es decir, el libro informativo para quién prepara un viaje a tierra desconocida. Si el libro de viaje propiamente dicho es una narración retrospectiva hecha por un viajero foráneo, una vez finalizado el periplo, con la intención de contar su experiencia del mismo, la guía es de intención mucho más modesta y aplicada: una descripción de las características y datos útiles del país a visitar, de finalidad prospectiva pues está destinada a los presuntos viajeros interesados en aprovechar al máximo el recorrido y redactada generalmente por un nativo buen conocedor del país a visitar. Por eso aquéllos, en cuanto obra de creación personal, tienen amplias potencialidades de creatividad estética, mientras que éstas, muy al contrario, se mueven en el terreno de lo descriptivo, informativo y meramente estadístico. 
Tradicionalmente se viene admitiendo como antecedente más remotos de este tipo de guías o repertorios informativos la obra de Pausianas, marino griego del siglo II d.C. que escribió una Descripción de Grecia en un estilo informativo y escasamente literario, pero de contenido muy preciso y detallado, como se confirmó a posteriori por los descubrimientos arqueológicos. Por eso, la obra de Pausianas gozó de gran aceptación entre los primeros viajeros europeos que, carentes de guías más recientes, visitaron la Grecia clásica desde finales del XVIII y durante todo el XIX y pusieron de moda el texto clásico. Fueron pues éstos, y no su autor del siglo II, los auténticos responsables de que la Descripción pueda considerarse como una primera guía de viajes y de la correspondiente fama de la gozó entre los viajeros ilustrados y románticos.

Pero pronto surgieron imitaciones adaptadas ya a las necesidades de los nuevos tiempos y viajes. En 1828, Friedrich Röhling, un editor alemán de Coblenza, había publicado una guía para el viajero que pretendiera recorrer el Rin entre Maguncia y Colonia (Rheinreise von Mainz bis Köln), otro de los itinerarios preferidos para el imaginario romántico de la época, que tuvo bastante aceptación. Cuatro años después el negocio y la idea de Röhling fueron adquiridos por otro editor alemán, Karl Baedeker, cuyo nombre estaba destinado a convertirse en sinónimo de guía de viaje. En efecto, durante la mayor parte del siglo XIX las guías Baedeker fueron referencia obligada para todo viajero que pretendiera visitar cualquier rincón de Europa, pues, junto a la precisa descripción de los paisajes y monumentos, incluía también información sobre transportes, alojamientos, precios y otras curiosidades de utilidad en cualquier viaje y que hoy día consideramos imprescindibles en cualquier guía turística.

Durante cuarenta años, entre 1878 y 1918, las guías Baedeker fueron traducidas al inglés por dos editores escoceses, los hermanos James y Findlay Muirhead, que publicaron también algunas de las guías de países anglosajones, como EE UU y Canadá. Pero la feliz colaboración quedó rota con la Primera Guerra Mundial que obligó a los citados editores escoceses a independizarse de la firma alemana y buscar la alianza de la editorial francesa Hachette, que había publicado también algunas guías de su propio territorio y un itinerario descriptivo, histórico y artístico de Italia en 1855, de A. J. du Pays. De esta colaboración surgieron las famosas Guías Azules, que se diferenciaban así del color rojo que servía de encuadernación y sello a sus antecesoras alemanas. Colección de guías que, bajo el sello de la famosa editorial francesa, coparon el mercado turístico editorial durante gran parte del siglo XX. 
De principios de esa centuria data también otra publicación de este mismo tipo, icono de una actividad y de toda una época. Bajo el nombre genérico de guías Michelin se engloban una serie de publicaciones de esta marca de neumáticos, originariamente de carácter publicitario, que han terminado teniendo más aceptación que los productos originales. En 1900, el propietario de la marca André Michelin creó la primera de esas guías, la de color rojo, que junto con los datos prácticos de todo viaje, contenía una serie de informaciones gastronómicas que la han concedido fama universal. Más adelante vendrían las guías de itinerarios (de color verde), las regionales, los mapas de carreteras, etc. que constituyen hoy día la más completa colección al respecto.

En España carecemos de colecciones y publicaciones similares a las citadas hasta época reciente. Como antecedente inmediato se puede citar las Ilamadas "guías de forasteros", publicación semioficial, mitad información turística y mitad almanaque de sucesos, que se editaban periódicamente, la primera lo fue en Madrid en 1722, y lo siguieron haciendo de otras ciudades españolas a lo largo de los siglos XVIII y XIX. Pero las guías turísticas propiamente dichas necesitaban un mercado de posibles viajeros inexistente en nuestro país hasta finales del pasado siglo. Éramos, en efecto, país de destino turístico, pero nuestros visitantes venían con sus guías desde sus países de origen, como es el caso del Baedeker, cuya primera edición de la Guía de España y Portugal data de 1898. Los pocos españoles con disponibilidades para iniciar su periplo turístico podían servirse fácilmente de las colecciones citadas, ya fuera en su idioma original o traducidas. Aunque ello no quiere decir que no contemos con un amplio repertorio de guías sobre ciudades, comarcas o parajes de la península, que configuran lo que María del Mar Serrano (1993) ha llamado con acierto: "viajes de papel".

Según esta autora, que ha reseñado unas dos mil guías de España editadas entre los años 1800 y 1902, sólo 849 podrían ser consideradas propiamente como tales y, entre éstas, la variedad es notable (urbanas, provinciales, locales, regionales, etc.). El resto son libros y guías de naturaleza diversa: artístico-monumentales, guías de ferrocarriles, de balnearios, nomenclátores, callejeros, almanaques, etc. que, a pesar de su interés, escapan de momento a nuestra atención.

Entre las guías urbanas predominan las de Madrid (López y Mesonero), Barcelona (Bofarull y Cornet) y Valencia (Boix y Cruilles). Hay que destaca como hecho significativo las dos guías de Granada, publicadas por Ganivet, y entre las locales las de Aranjuez y El Escorial, etc. Entre las guías regionales, existente varias ediciones relativas a Cataluña e Islas Baleares, y las provincias 
de Madrid, Barcelona y Guipúzcoa son las que cuentan con más guías sobre las mismas (Serrano, 1993:, págs. 68-75).

\section{LAS GUÍAS GEOGRÁFICAS: TURISMO, LITERATURA Y GEOGRAFÍA}

Muchas de las obras citadas permiten apreciar como se pasa del interés turístico del viajero al más intelectual del lector culto que, por ello, atiende más a la descripción y a la narración que a la mera información. Ello es patente sobre todo en un tipo específico de guías, formalmente turísticas, pero de intencionalidad y concepción mucho más geográfica y literaria, que aparecen por las mismas fechas y van adquiriendo personalidad propia a lo largo de los dos últimos siglos. Este tipo de libros se parecen mucho más a los de viajes que a las guías propiamente dichas, pero no son tales, pues presentan notables diferencias con aquéllos. El autor, en primer término, no es el viajero foráneo que recorre el país, sino un paisano buen conocedor del mismo que lo describe, interpreta o incluso recrea. No se describe los lugares que se visitan, sino aquellos en los que se vive o ha vivido, pero que se cuentan como si se visitaran, pensando en aquellos que quieran hacerlo y prescindiendo conscientemente de las informaciones puntuales que caracterizan a las guías turísticas propiamente dichas. Y de esos lugares no se describe la impresión del viajero, la percepción de una primera visita, sino el conocimiento profundo del espacio vivido, las descripciones de otros a través del filtro del autor.

Son éstas las que ahora nos aquí interesan: descripciones de espacios y lugares que superan con mucho el concepto de guía para convertirse en una auténtica narración del territorio en la que éste es el argumento y su esencia el protagonista. Por ello constituyen, en algunos casos, auténticos libros de Geografía cultural y descriptiva a la vez, que enriquecen la forma de abordar el estudio del territorio, aunque de forma peculiar.

Es difícil precisar el origen y razón de este tipo de obras. Frente a la perentoria necesidad de información de quién va a iniciar un viaje o el deseo de relatar el ya realizado, ¿qué es lo que lleva a un escritor a describir la propia tierra como si, sin serlo, de un viajero se tratara? La razón tal vez haya que buscarla en el viaje de ficción, el nunca realizado ni realizable, aunque muchas veces pensado y programado. Viaje que se utiliza como pretexto para justificar y ordenar la descripción. Son los viajes de salón, biblioteca o mesa camilla, que se realizan con la imaginación más que con cualquier otro medio de transporte y que constituyen también, 
como el viaje propiamente dicho, una especial fuente de conocimiento para el geógrafo. Por eso decía Ramón Gómez de la Serna que "el mejor viaje es el dedo sobre el mapa". Recuérdese también que el nombre completo de la famosa obra de Richard Ford es Manual para viajeros por España y lectores en casa. Ambos autores son exponentes de una época caracterizada por el viaje culto y burgués, de aprendizaje, disfrute y conocimiento, opuesto al turismo masificado de nuestra época, impersonal y proletarizado, y que requiere de una preparación intelectual previa, además de la más inmediata e instrumental de horarios de trenes y precios de fondas. Aldous Huxley, otro famoso autor y viajero, que podríamos incluir en la misma nómina, aconsejaba dedicar el mismo tiempo a la preparación del viaje que al viaje mismo y leer todo lo publicado sobre las tierras a visitar. A esta mentalidad, geográfica, turística y literaria a la vez, responde sin duda el tipo de obras que ahora nos ocupa.

A diferencia de los libros de viaje tradicionales o de las guías convencionales es difícil rastrear el origen de este último tipo de guías, dado la dificultad para diferenciarlas de otras publicaciones similares. En el caso español, se podría pensar como un precedente bastante representativo algunos libros del Viaje literario de Villanueva, si no fuera por su concepción erudita y el objeto de la investigación que le dio lugar. Más adecuado nos parece la cita de una publicación muy representativa de nuestro siglo XIX, los once volúmenes de Recuerdo y bellezas de España, obra que pretendía recopilar, mediante dibujos y pinturas tomados del original, los más representativos monumentos del país, junto con una descripción de los mismos y unas notas sobre la historia y la geografía de la zona a la que pertenecían. La obra estuvo al cuidado editorial, litográfico y artístico de un pintor catalán, Francisco Javier Parcerisa (1803-1875), que realizó la mayor parte de los grabados mediante una cuidada técnica que recuerdan a la de Laborde. Las descripciones geográficas y artísticas fueron realizadas por importantes escritores de la época: Francisco Pi i Margall (Granada), Pablo Piferrer (Cataluña), Pedro de Madrazo (Córdoba, Cádiz y Sevilla) y, sobre todo, José María Quadrado que redacto el resto de la de la obra, por lo que, junto a Parcerisa, se le considera como el autor por antonomasia de la misma.

Las obra, considerada por F. R. Rafols como "una de las obras cumbres del romanticismo español", comenzó a publicarse en Barcelona en 1839, con el primer tomo relativo a Cataluña, y siguió trabajosamente con los del resto de España, aunque a la muerte de Parcerisa, la obra quedó inconclusa. Nueve años después, en 1884, la editorial Daniel Cortezo reimprimió la 
obra actualizada y los dos últimos tomos que faltaban, con el nombre de España, sus monumentos y artes, su naturaleza y su historia ${ }^{1}$.

En este mismo sentido, pero de menor trascendencia, pueden citarse otras obras similares que se publicaron en el siglo XIX. Así, Emilio Valverde y Álvarez escribió varias guías regionales (País Vasco, Navarra, Cataluña, Aragón, etc.) publicadas entre 1884 y 1887 en Madrid, por la imprenta de Fernando Cao y Domingo del Val, y unos años después (1890-1900), Valentín Picatoste García publicaba una Descripción e historia política y eclesiástica y monumentos de España para uso de la juventud, estructurada a escala provincial (Guadalajara, Ávila, Segovia, Salamanca, Valladolid, Palencia, Madrid, Burgos, Álava, Granada, León). Por las mismas fechas, 1888, los hermanos Giner de los Ríos: Francisco y Hermenegildo, publicaron una interesante obra de poco más de 300 páginas: Portugal impresiones para servir de guía al viajero, que por su enfoque más actual y próximo al que pretendemos estudiar y la trascendencia intelectual de los autores constituye toda una muestra de este tipo de literatura geográfica.

\section{LAS GUÍAS GEOGRÁFICAS DE ESPAÑA EN EL SIGLO XX}

A lo largo de la pasada centuria este tipo de publicaciones fueron generalizándose según aumentaba el mercado editorial y el atractivo turístico de España. Entre las numerosas publicaciones aisladas, de muy diferente rigor y calidad, que podríamos citar al respecto² ${ }^{2}$ destaca una colección de Guías de España editadas en los años treinta del siglo pasado por le Patronato Nacional de Turismo y publicadas por Espasa Calpe, editorial con una clara vocación hacia este tipo de obras y que evidencia el comienzo de la preocupación pública por las potencialidades turísticas de nuestro país3.

Pero es después de la Guerra Civil cuando este tipo de publicaciones van a ser más comunes, con algunas colecciones representativas, aparte de la de Ediciones Destino. Por ejemplo, la editorial catalana Juventud dedicó una amplia atención a este tipo de guías, con varias colecciones muy

1. Ediciones El Albir, de Barcelona, reeditó la colección completa en 1978.

2. Valgan como ejemplo, que no pretende ser exhaustivo, la Guía de Galicia, de Ramón Otero Pedrayo (1945), Editorial Galí, y la de Cuenca, de César González Ruano, publicada en 1956 por Planeta.

3. En esta colección podemos citar las guías de Sevilla de Santiago Montoto, de Córdoba de Rafael Castejón, de Santander, de Elías Ortiz de la Torre, y de Tarragona, de Joaquín Navascués, entre otras. 
representativas de esta literatura geográfica. Destacan particularmente dos de ellas, de orientación muy diferente. La más antigua, Ilamada Tierras y Mares, se publicó en los primero años de la posguerra y la formaban libros casi de bolsillo, de 150-250 páginas encuadernados en rústica, con dibujos y unos pocos mapas como única ilustración, alternando traducciones de viajes y aventuras foráneas con guías autóctonas de autores españoles de reconocida solvencia ${ }^{4}$. Dirigida a una potencial mercado emergente de lectores de clase media, pero de escaso poder adquisitivo entonces.

La otra colección de Juventud, más moderna, se editó hasta principios de la década de los setenta. Se encuadraba bajo la denominación genérica de Bellos Países y se publicó en dos etapas sucesivas, variando algunos caracteres editoriales a partir de 1965, pero conservando la unidad de la colección. Se trata de traducciones francesas, de la Editorial B. Arthaud (París-Grenoble) en su mayoría, relativa a viajes y descripciones de países y territorios extranjeros, que incluyen algunas importantes obras relativas a la península lbérica, por lo que la incluimos aquí ${ }^{5}$. Tomos de un formato mayor (18 x 23, salvo excepciones), de más de 250 páginas, ilustrados con abundantes y ricas fotografías, lo que denota un tipo de lector con mayores posibilidades e interés. En la presentación de la colección se describe con claridad el objetivo y carácter de ésta, que se ajusta, como puede verse, a nuestro objeto:

"No es una serie de guías a la manera tradicional, sino una biblioteca de monografías bellamente escritas por los mejores especialistas que, aportando toda la documentación y las orientaciones y sugerencias que pueda apetecer el turista, ofrecen al lector no viajero una visión múltiple, viva y actual de los países y ciudades que estudian, profundizando en su presente y en su pasado."

4. Formaban parte de dicha colección, entro otros títulos los siguientes: Edgar Lajtha: Japón. Ayer, hoy y mañana. E. Wrigth: La gran cuchara de asta. Viaje por la India y el extremo oriente. Jose $M^{a}$ de Sagarra: El camino azul. Viaje a la Polinesia. Luis Díez del Corral: Mallorca. R. Gay de Montellá: Mediterranismo y Atlantismo. Tres ensayos. Erling Bache: Hombres blancos en los trópicos. Príncipe Guillermo de Suecia: Entre pigmeos y gorilas.

5. Los títulos más significativos de esta colección eran: Y. y E. R. Labande: Roma. Andre George: París. Jaques Boussard: Londres. Yves Bottineau: España. Jean Sermet: España del Sur. P. Deffontaine y M. Durliat: España del Este. Claude Artaud y F. Herbert. Stevens: Los Andes. Techo de América. Maurice Ricord. Cruceros por el Mediterráneo. Jeanne y George Roux: Grecia. Yves Bottineau: Portugal. Eugene Susini: Austria. Pierre Borel: La Costa Azul. Gabriel Faure: Venecia. Y. y E. R. Labande: Florencia. Jean Louis Colas: Baleares. Léonard Cottrell: Egipto. Pierre Morel: La ciudad de Carcasona. 
Junto a este tipo de obras se pueden citar otras más especializadas, en temas artísticos o patrimoniales por ejemplo, dirigidas a un público más experto. Es el caso de la colección Guías Artísticas de España, publicadas a lo largo de casi treinta años por la editorial Aries de Barcelona, bajo la dirección inicial de José Gudiol, en la que participan distinguidos historiadores del arte, pero aunque es el territorio provincial quien delimita la temática de la guía, su contenido y objetivo es claramente artístico por lo que se aparta de nuestro objetivo. Algo parecido podría decirse con la espléndida colección Tierras de España, publicados por la Fundación March en la segunda mitad de los setenta, en lujosos libros, que cuentan con excelentes introducciones geográficas, pero su finalidad es esencialmente artística. Y lo mismo ocurre algunas guías provinciales editadas por instituciones locales, con colaboraciones de autores de prestigio, ricamente ilustradas y editadas, presentaciones de cargos públicos provinciales ${ }^{6}$.

Por el contrario, otras colecciones de la época, como El Mundo en Color de Ediciones Castilla, son de objetivo mucho más ligero, buscando más el entretenimiento; o también la colección Andar y ver, guías de España, de la Editorial Noguer, luego retomada por Everest, guías de bolsillo, de breve texto y abundancia fotográfica ${ }^{7}$. A partir de los setenta, este tipo de publicaciones se generaliza y masifica, en lógica correspondencia con los cambios en el país, y la mayoría de ellas escapan a nuestro estudio. Pero durante más de cuarenta años, estas guías turísticas fueron un tipo de libro no sólo de interés geográfico, en cuanto forma particular de hacer geografía, sino también sociológico, como muestra de la existencia un tipo lectores interesados por estos temas en las postrimerías de lo que ha sido dado en Ilamar "Galaxia Gutemberg", cuando ya despuntaban otros soportes más adecuados para difundir paisajes y países, y que, en nuestro caso, coincide además con los finales del Franquismo.

En efecto, la mayoría de estas publicaciones, tanto las traducciones como las de redacción originaria en castellano, presentan unas notas comunes, que se evidencian en los subtítulos de libros y colecciones: andar y ver, tierras y hombres, bellos países, lugares turísticos, caminos y viajeros, etc. con secciones características, como "saber vivir internacional", "el mundo en la mesa", "la vuelta a España en ochenta libros", etc. Títulos que denotan, en primer término, una clara atención por lo lúdico, el viaje y la recreación,

6. Como ejemplo: Segovia, camino para el viajero y Burgos, Tierra y Hombres.

7. No hay que olvidar las la Guía de Duratón, Los Oscos y El Hierro, de la colección "Guías Raras" de la Subsecretaría de Turismo. 
que parece apuntar a un tipo de literatura de evasión respecto a los problemas de la época. Pero en otros, sin renunciar a esa finalidad prioritaria, se busca también una descripción más comprometida relacionada con la narrativa de la época.

Durante los años cuarenta y cincuenta del pasado siglo, los españoles tenían escasas posibilidades de viajar, debido a la falta de medios económicos, a la deficiente estructura de transporte y alojamiento $y$, en ciertos casos, a las limitaciones de carácter político. Por eso, era la situación propicia para esta forma de viaje inmóvil, interior o de papel, en el que el libro y la guía se convierten en protagonistas, cobran una dimensión especial y sustituyen al viaje propiamente dicho, sobre todo si además se daba la calidad literaria de los autores y el atractivo de ediciones cada vez más cuidadas gráficamente. Tal fue el caso de las Guías de España de Espasa Calpe, que retomando la tradición de las publicadas por dicha editorial, en colaboración con la Dirección General de Turismo antes de la Guerra, se editaron en los años cincuenta y sesenta del pasado siglo. Estas guías, cuidadosamente editadas, fueron redactadas por escritores de prestigio, siguiendo un esquema regional de España en la que cada región era definida además, por una breve frase que pretendía sintetizar el sentido de la descripción ${ }^{8}$.

\section{Ediciones Destino y la COLECCión DE “Guías de EsPaña”}

Pero las guías de Espasa-Calpe no fueron las únicas, ni siquiera las primeras editadas en España tras la Guerra Civil. Esa consideración le cupo a otra colección también emblemática para la época: la formada por las dieciséis guías de España de Ediciones Destino, publicadas entre 1943 y $1977^{9}$ que constituyen el principal tema de atención de este trabajo. No pretendemos

8. Así, Asturias, de Juan A. Cabezas, era definida como "biografía de una región"; Galicia, de José $M^{a}$ Castroviejo, era "la guía espiritual de una tierra"; Extremadura, del conde de Canilleros, la "tierra en la que nacían los dioses"; Valencia, de Luis Guarner, "tierra y alma de una país", etc.

9. Estas dieciséis guías fueron: José Pla: Guía de la Costa Brava (1941/48) y Mallorca, Menorca e Ibiza (1950); Carlos Soldevila: Barcelona (1951); Pío Baroja: El País Vasco (1953); Juan Ant. Cabezas: Madrid (1954); Carlos Mtez. Barbeito: Galicia (1957); José Ma Pemán: Andalucía (1958); José Pla: Cataluña (1961); Joan Fuster: El País Valenciano (1962); Gaspar Gómez de la Serna: Castilla La Nueva (1964); Claudio de la Torre: Gran Canaria, Fuerteventura y Lanzarote (1966); Alfredo Reyes Darias: Tenerife, La Palma, La Gomera, El Hierro (1969); Dolores Medio: Asturias (1971); José Vicente Mateo: Murcia (1971); Dionisio Ridruejo: Castilla La Vieja (2 t., 1974): Santiago Lorén: Aragón (1977). 
tratar aquí las vicisitudes de la editorial y su contribución a la cultura literaria del país, ni tampoco su evolución ideológica ni las de sus principales editores y colaboradores, aspectos todos ellos que han merecido atención pormenorizada en otras ocasiones. Pero si quisiéramos ver hasta qué punto todas esas variables se vieron reflejadas en la colección de guías de España, obra en principio marginal al núcleo temático de la editorial, o al menos eso cabría esperar de unos libros que pretendían una finalidad más lúdica que comprometida.

El origen de la editorial, como es sabido, fue la revista del mismo nombre fundada en Burgos en 1937 por varios periodistas y escritores catalanes: Josep $M^{a}$ Fontana, Xavier de Salas, Josep Vergés, Ignasi Agustí, J. Ramón Masoliver, entre otros (Geli y Huertas, 1991), relacionados con el Servicio de Prensa y Propaganda de los sublevados, a cuya cabeza estaba entonces Dionisio Ridruejo. Terminada la guerra trasladaron su redacción a Barcelona y algunos de ellos: Vergés, Agustí y el poeta Joan Teixidor, ampliaron la oferta cultural de la revista, dirigida por Agustí, con la editorial del mismo nombre, que quedó al cuidado preferente de Vergés (Arroyo, 2006).

El compromiso político con el nuevo régimen duró poco, pero con algunos títulos representativos, como la Historia de la Segunda República de Pla, y eso con todas las reservas del caso. De forma que a la vez que los personajes citados, desde Ridruejo a Vergés, pasando por el mismo Pla, fueron evolucionando desde el ideario de los primeros momentos hacia formas más estéticas que políticas, lo mismo ocurrió con la editorial, que se orientó cada vez más hacia la literatura. En 1942 se publica el primer libro de la prestigiosa colección Ancora y Delfín (Cavilar y contar, de Azorín), en la que verían la luz obras maestras de la narrativa española de posguerra. Unos años después, en 1945, nacía el premio Nadal a iniciativa parece ser de Agustí, entonces ya novelista de fama tras el éxito de su Mariona Rebull, pero cuya idea fue inmediatamente acogida por Vergés y Teixidor, que acordaron darle ese nombre en recuerdo de Eugenio Nadal, redactor de la revista, fallecido poco antes. Al principio, el premio tuvo una repercusión más bien modesta, como el fallo, que se producía en una cena de amigos en el hotel Suizo, pero pronto la calidad de los premiados (Laforet, Delibes, Gironella, Sánchez Ferlosio, etc.) lo convirtieron en el más representativo de las letras españolas.

Durante esos mismos años cuarenta y cincuenta del pasado siglo, la revista también fue evolucionando hacia posiciones cada vez más democráticas, y acogiendo en su seno, como colaboradores permanentes o circunstanciales, a muchos escritores noveles o consagrados, cuyas obras eran 
publicadas por la editorial10. De esta forma, y como dijera el propio Vergés en entrevista a La Vanguardia, poco antes de su muerte: "Es imposible entender la editorial si no se habla de la revista". A este respecto resulta evidente el viraje de ésta desde sus iniciales simpatías germanófilas al apoyo a la causa aliada, que comienza con un artículo de Josep Pla titulado La sonrisa española. En esa época, era Pla uno de los escritores más representativo de revista y editorial. Natural de Palafrugell, como Vergés y amigo de éste desde antes de la guerra, tal como recordaba este último a La Vanguardia11, Pla era entonces el colaborador liberal laico, junto al liberal papista Brunet (Ridruejo, 1976, pág. 259) de la revista y autor favorito de la primera época ${ }^{12}$. Desde 1966 y durante casi veinte años, la editorial inició la titánica obra de publicar los 45 volúmenes de sus Obras completas, completada en 1975 por el Cuaderno gris, según la excelente traducción castellana de Dionisio Ridruejo que, a su vez y de forma paralela a la conocida transformación de su ideario político, fue evolucionando también desde su participación en los orígenes falangistas de la editorial, hacia la del colaborador asiduo en la revista, para terminar en columnista permanente e inestimable en los años finales de su vida. De esta forma se fue tejiendo una tupida red de relaciones personales, entre la obra literaria, la postura intelectual y los intereses editoriales que creemos se refleja también en la colección de guías de que nos ocupa ${ }^{13}$.

Junto a Pla y Ridruejo, fueron otros muchos grandes escritores de sucesivas generaciones, en castellano y catalán, los que completan la historia de la revista y de la editorial: Baroja, Torrente Ballester, Umbral, Néstor Luján,

10. Es el mismo Ridruejo, testigo de excepción de esta historia, se atrevió a resumirla "en una especie de chiste. Iniciada como publicación falangista (...) fue introducida en lo hogares catalanes como, si dijéramos, con bayonetas. Pero, de pronto, cuando los suscriptores de compromiso se decidieron a leerla se llevaron una gran sorpresa: '¡Coi, però si aquesta és roba nostra!' (...) adquirió pronto una fisonomía liberal, aliadófila y moderadamente catalanista" (Ridruejo: 259).

11. "Las familias ya se conocían (...) el reencuentro se produjo en el Paseo de Gracia tras la Guerra Civil (...) Pla salía de un café y me preguntó que hacía allí. Le contesté que estaba en una revista y que querría que colaborara. '¿Debes pagar poco?', fue su respuesta. 'Sí, pero pago siempre la mía'."

12. De Pla Destino publicó entre 1941 y 1948: Viaje en Autobús; Humor honesto y vago; El pintor Joaquín Mir; Un señor de Barcelona; La huida del tiempo y Vida de Manolo.

13. La relación entre Pla y Ridruejo se remonta a los años de la guerra y se mantuvieron estables durante largo tiempo. El primero evoca a Ridruejo con "afecte cordialissim", lo que no es óbice para que afirme de él que "com a poeta es decebedor". Por el contrario Ridruejo calificaba a Pla como "el mejor y el más fino y vibrante de los paisajistas literarios de la península" (Gracia, 2007, pág. 494). 
Cunqueiro, Zúñiga, Tristán la Rosa, Mañé, Porcel, Fuster, etc. además de los antes citados que, junto a los lectores: "una tipología ciudadana: gente culta, de clase media aposentada, que no disponía de los habituales alimentos espirituales de antes de la guerra" (Geli y Huertas, 1991) y una generación de editores catalanes excepcional, en la que, además de Vergés, Teixidor y sus compañeros de Destino, habría que situar a Lara, Janés, Grijalbo, Bruguera, Plaza, Caralt, Salvat, etc., configuran un momento, también excepcional, de la historia editorial española.

Con el tiempo y el cambio de las condiciones políticas y económicas, la revista fue perdiendo interés. Para unos fue la competencia de otras publicaciones nacidas del mismo impulso democratizador, para otros el sesgo partidista y personalista que fue tomando en la lucha política cotidiana ${ }^{14}$. Tras una efímera recuperación en 1985 dejó de publicarse poco después. Otro tanto pasó con la editorial, adquirida en su totalidad por Planeta en 1996, que siguió con su sello distintivo dentro de ese grupo editorial, pero con diferente carácter y objetivos.

Pues bien, cabría preguntarse: ¿qué papel jugó en esta historia la publicación de las guías que ahora nos interesan? Como ya hemos dicho en otro lugar (Arroyo, 2006), es probable que al principio no se pensara en una colección que abarcara toda España, por eso el carácter turístico de las primeras guías. Pero es evidente que, desde que la editorial se embarcó en un proyecto global, el enfoque fue muy otro y se fue configurando en los sucesivos volúmenes, que es lo que pretendemos estudiar aquí.

A este respecto es necesario manejar tres variables que convergen en la redacción definitiva de la obra que comentamos. La primera es el tiempo, el largo periodo transcurrido desde la primera edición de la Guía de la Costa Brava, de Pla (1941) a la de Aragón de Santiago Lorén (1977) casi el mismo tiempo que duró el franquismo y sólo unos años menos que lo hizo la propia editorial, antes de su integración en Planeta. No fue un tiempo cualquiera, sino de profundos cambios en todo el país, tal vez los más transcendentales de su historia reciente. Así, por ejemplo, no es la misma Costa Brava la que describía Pla en los cuarenta, cuando redactó su guía, que la que existía en los setenta cuando, por ejemplo, Dolores Medio hizo lo propio con la suya de Asturias, por lo que nos encontramos con realidades geográficas difícilmente comparables. Ni tampoco eran los mismos gustos, tendencias y estilos narrativos, inquietudes sociales o políticas las que van a primar en una época y en otras.

14. Verges vendió la revista a Jordi Pujol, en 1975, haciéndose cargo Baltasar Porcel de la dirección. 
La segunda es la tierra, las mismas diferencias regionales objetivas de esta península, tantas veces citadas y enumeradas a lo largo de la historia, y que el mismo Dionisio Ridruejo, uno de los protagonistas de esta colección veía así: "En ningún estado europeo, ni siquiera en Italia, ni siquiera en Inglaterra, se recorren tantos países diferenciados, con fisonomía de caracterización tan profunda, como en esta península donde vamos viviendo" (Ridruejo, pág. 187). Sentir común, desde el 98, de muchos escritores españoles de la época, más allá de las diferencias objetivas propias de un país mediterráneo, pero que al principio de la colección eran vistas como simples matices en la "unidad entre los hombres y las tierras de España" y al final terminaron convirtiéndose en señas de identidad distintivas de una España autonómica e incluso plurinacional.

La tercera variable son los autores, cada uno de su libro naturalmente, aunque al final resultara una colección bien coordinada. Cada guía es, a estos efectos, una obra autónoma en la que se vierte la relación personal e intransferible entre hombre y tierra, el autor con su región. El mismo Ridruejo, queriendo justificar precisamente esa ausencia de relación entre los escritores castellanos con su tierra, la compara con la existente en otras regiones españolas: "Páginas equivalentes a las que, cada uno a su modo, han dedicado Pla al Ampurdán, Juan Ramón a Huelva, Baroja al País Vasco y el mismo Blasco a la huerta valenciana o Pereda a la Montaña, no se han dado aquí (en Castilla) más que raramente" (Ridruejo, 1976, pág. 186). Y no sabemos hasta que punto fue o no casualidad que de los cinco casos citados por Ridruejo, dos de ellos, coinciden con guías de Destino, que serían tres si incluyéramos la del mismo Ridruejo.

\section{LOS AUTORES Y SU OBRA}

Tal vez la nota más característica de esta colección fue la espectacular relación de autores que, con ligeros matices, redactaron las correspondientes guías. Catorce escritores, entre 1943 y 1977, desde el novelista más importante de nuestro siglo XX hasta personajes mucho menos conocidos en el ambiente literario o geográfico, que se fueron solapando en el tiempo, pues algunos casi no habían nacido cuando se publica la primera guía y muchos de ellos habían fallecido ya cuando lo hace la última.

En todo este colectivo, el protagonismo editorial, más que literario, les corresponde a las gentes de la generación del 1936-1939, la de nacidos a principios de la segunda década del siglo y que alcanzan su madurez con 
el conflicto. De ella forman parte, entre los autores, Ridruejo, Dolores Medio, Gómez de la Serna o Martínez Barbeito, pero es, ante todo, la de los promotores de Destino: Teixidor, Agustí, Vergés, etc. y la de otros muchos profesionales, fotógrafos, dibujantes, cartógrafos, que tomaron parte en la realización del proyecto. Es lógico que ello fuera así. Como obra de posguerra, la editorial y sus principales proyectos: premios, colección y línea directiva, estuvo largamente protagonizada por las gentes que sufrieron los embates de la guerra y las contradicciones de la victoria. Por eso, a los ojos de algunos de sus más importantes integrantes, fue una generación "destruida" (Díaz Plaja), "perdida" (Ros) o, peor aún, "quemada" como la autodenomina Masoliver, tan unido al grupo de Destino. Sin maestros, como dice Manjón-Cabeza (2008), refiriéndose a este grupo generacional en el terreno de la poesía, pero que podemos generalizar a otros ámbitos, su principal función fue la de servir de puente y de recuperar los valores perdidos en la contienda, según la decepción y la autocrítica iba generalizándose entre las figuras más representativas del grupo.

Sin duda ese fue el caso de Ridruejo, que por su valor referencial puede ser considerado como paradigmático, pero también el de los editoresfundadores de Destino. Falangista desde 1933, Ridruejo atravesó todos los estadios ideológicos de la política de su tiempo: desde la Jefatura de los Servicios de Propaganda de los vencedores hasta la pública y total oposición Franquismo, con etapas de poder, de destierro y de cárcel. Pero además en Ridruejo está también el escritor, el poeta comprometido con la cultura y con la ideología, lo que se refleja en algunos de sus libros, como Escrito en España y singularmente en la Guía de Castilla la Vieja, que publicó al final de su vida. El caso de Dolores Medio es algo diferente. Nacida en Oviedo, en 1911, su carrera literaria empieza en 1945, al concedérsele el premio Concha Espina de novela corta. Pero su consagración definitiva no llegará hasta siete años después al ganar el Nadal de 1952 por Nosotros los Rivero, lo que la supondrá su relación con Destino. Además de su principal dedicación a la novela, Dolores Medio practico también la narración histórica, en una biografía de Isabel II y la descripción geográfica y literaria, en su Asturias, que ahora nos ocupa, contando para ambos proyectos con sendas ayudas de la Fundación March.

Por último, cabría incluir en este mismo grupo generacional a Gaspar Gómez de la Serna, sobrino de Ramón, y excelente escritor con importantes estudios sobre los libros de viajes (Los viajeros de la llustración) además de diversas guías de carácter literario y artístico (Guía de Toledo. Guía del Camino de Santiago, etc.) y la Guía de Castilla la Nueva que ahora 
comentamos 15 ; y también a Carlos Martínez Barbeito, moderado galleguista antes de la guerra, amigo de Lorca y colaborador en el Departamento de Cinematografía del Servicio de Propaganda que dirigía Ridruejo. Ello le facilitó, años después, la adaptación al cine de alguna de sus novelas ( $E$ I bosque de Ancines), así como su vinculación con el grupo de Destino y, a través de ésta, seguramente del encargo de escribir la guía de su tierra (Ridruejo, 1976, pág. 136).

Pero como generación puente, lo normal es que sus protagonistas se fijaran más en los escritores de generaciones anteriores, para buscar en ellos los referentes editoriales de nuevos proyectos y, entre ellos, a los autores para las guías de España de los primeros años. Es ante todo el caso de Josep Pla, nacido en 1897 y por lo tanto miembro, aunque sea sólo desde el punto de vista cronológico, de la generación de 1927. Pla era ya un escritor sobradamente conocido desde antes de la guerra, por sus artículos en La Veu de Catalunya, de Cambo y por su excelente prosa narrativa. Tras la contienda colabora en La Vanguardia16, y sobre todo con Destino, como ya hemos dicho, que durante años se convierte en su principal editorial. Por ello, dado su estilo y condición literarias no tiene nada de particular que se convirtiera en el inspirador, consciente o no, de la colección que comentamos. Narrador paisajístico por excelencia, la primera edición de su Guía de la Costa Brava (1941) debió concebirse como libro aislado justificado en si mismo, uno más de los que el genial escritor ampurdanés dedicó a describir tierra y viajes. El éxito del libro pudo ser el germen de la idea del resto de la colección (Arroyo, 2006).

Para ello, había que recurrir a otros autores más allá del círculo inmediato de Destino y de la cultura catalana de posguerra. El más significativo de ellos, dada su personalidad literaria, fue Baroja, que recibió el encargo de escribir una Guía del País Vasco a finales de los años cuarenta. Para entonces D. Pío era ya un escritor totalmente consagrado. Académico desde antes de la guerra, había publicado ya sus principales novelas, incluso sus memorias. Su escepticismo, rebeldía y radicalidad definían ya todo un estilo literario, dentro de la generación más importante de nuestras letras contemporáneas. En toda su obra Baroja se muestra como un permanente viajero, buen conocedor de España y excelente narrador de su tierra. Gran

15. Gaspar Gómez de la Serna es uno de los pocos autores de la colección, que de forma explícita, se considera miembro del "núcleo de la generación del 36 en que me encuentro" (rev. Alférez. I.4: 1).

16. Colaboración que no debió ser muy satisfactoria desde la marcha de Manuel Aznar, al que Pla Ilamaba "el Rubio" (Ridruejo, 1976, pág. 184). 
aficionado además a los libros de viajes, a los que se refiere en algunos pasajes de sus novelas. ¿Quién podría argüir mejores títulos para escribir un libro sobre el País Vasco, con ese nombre, que incluyera Navarra y las provincias francesas?

En tercer lugar, miembro también de la generación del 27, contemporáneo y coetáneo de Pla, fue José María Pemán, que vivió en los mismos años que el escritor catalán (1897-1981) e ingresó en la Real Academia el mismo años que Baroja (1935). Pemán cultivó con maestría diversos géneros literarios, desde el periodismo al teatro, y casi siempre, mostró cierta predilección por los temas de su tierra, lo que le convirtió en especial candidato, a los ojos de Vergés, para escribir la Guía de Andalucía. Además, la moderación ideológica de Pemán, sin menoscabo de su calidad literaria y su ligera disidencia monárquica, permitía equilibrar la nómina de colaboradores de la colección, en principio más sesgada hacia posiciones críticas con el régimen triunfante.

Ello no era una cuestión menor, sobre todo teniendo en cuenta los antecedentes de algunos otros colaboradores de las primeras guías, como Carles Soldevila, que aporta la perspectiva moderadamente catalanista en esta primera etapa. De familia liberal, Soldevila era un escritor conocido que había publicado varios libros y ensayos antes de la guerra, a cuyo fin, temeroso de represalias, se exilió en París. Vuelto a Barcelona dedica su atención preferente a escribir sobre la ciudad: Gracias y desgracias de Barcelona (1943), Un siglo de Barcelona (1946), Històries barcelonines (1950) y la Guía de Barcelona, de Destino, resumen y culminación, en cierta manera, de una posición "ciudadanista" que va más allá del simple interés urbano para encubrir toda su ideología sobre Cataluña y lo catalán.

El otro caso, igualmente representativo, es de del asturiano Juan Antonio Cabezas, escritor y periodista, colaborador de varios periódicos, como Avance de Oviedo y El Sol y $A B C$ de Madrid, que fue condenado a muerte en 1938, no siendo definitivamente indultado hasta 1944. Cabezas fue un agudo cronista de Madrid, ciudad a la que dedico au atención en varias obras descriptivas y literarias, como Diccionario de Madrid; Cervantes en Madrid; Madrid, escenarios y personajes, etc. que se inician precisamente con la guía de Destino. En la misma generación podemos incluir, por último, al canario Claudio de la Torre, nacido en 1895, hombre polifacético de enorme creatividad: periodista y novelista, Premio Nacional de Literatura en 1924, autor y director teatral e incluso director de cine en un corto periodo de su vida, antes de la Guerra Civil. En 1963 escribió un ensayo Geografía y quimera, evocaciones sobre sus islas, que le introdujo en el ámbito de la 
descripción geográfica y literaria que desarrollaría en la guía de Destino tres años después.

Junto a este núcleo central de autores de generaciones anteriores a la guerra, o inmediatamente posteriores a la misma, se va incorporando otros autores entonces más jóvenes, según pasaba el tiempo, salían nuevos volúmenes y cambiaban las circunstancias sociales de la época. Así, podemos también citar a un grupo de escritores de la llamada generación de los cincuenta, que otros, más precisos, sitúan en el entorno de 1954. Es el caso del poeta y pintor tinerfeño Alfredo Reyes Darias, nacido en 1921, autor de varios murales en distintos edificios de sus islas, en los que predominaba temas de ambiente canario, pues en todo momento se mostró como un gran conocedor de la historia y de la geografía de estas islas. Fue director del Museo del Cabildo, primer director del Instituto Colombino de La Gomera y conservador del palacio de Capitanía, recibiendo en 1968 el encargo de Destino para redactar la guía de las Islas Canarias occidentales.

Más representativo es el caso del escritor valenciano Joan Fuster, nacido en Sueca en 1922, que dedicó la mayor parte de su producción literaria al estudio de temas sobre la personalidad del pueblo valenciano y sus raíces comunes con los países catalanes, con algunas obras clásicas al respecto (Nosaltres els valencians) o la Guía del País Valenciano, recibiendo, por todo ello el Premi d'Honor de les Lletres Catalanes en 1975.

En este mismo grupo generacional, aunque en el límite cronológico con la anterior, se puede incluir a otro médico y escritor, el aragonés Santiago Lorén, nacido en Belchite en 1918, es decir en el tránsito con la generación anterior. Lorén fue premio Planeta en 1953 por Una casa con goteras y premio Ateneo de Sevilla en 1984, por su novela El molino de aceite. Autor además de otros muchos ensayos y biografías sobre su tierra y profesión. Por último, la nómina de autores de la colección se completa con la del murciano José Vicente Mateo, nacido en Jumilla en 1931, empleado de banca, político en activo a finales del franquismo y autor de varios ensayos sobre su tierra de los que la guía de Destino es muy representativa.

\section{LA VISIÓN DE ESPAÑA EN LAS GUÍAS DE DESTINO}

El producto final es la citada colección de dieciséis guías, en diecisiete volúmenes cuidadosamente encuadernados, con un total de más de 9.000 páginas, además de innumerables fotos, mapas, ilustraciones, etc., y que, como hemos visto, se fue configurando a lo largo de más de treinta 
años, en los que también evolucionó, de forma paralela, la editorial que las publicaba y el país que describían. Pero para el lector que, otros treinta años después de acabado el proyecto, se acerca a esta espléndida colección, la sensación no puede ser más que la de encontrarse ante una obra completa y acabada, concebida así desde un principio, tal como la vemos en la actualidad. Pero no debió ser así, o al menos no lo fue en su totalidad ${ }^{17}$. El estudio más detallado de estas guías pone de manifiesto la existencia de varios criterios superpuestos y solapados, de diferentes etapas de redacción e incluso de distintos criterios editoriales. A estos efectos hemos agrupado las mencionadas guías en distintos grupos teniendo presente la personalidad de los autores, las similitudes o diferencias en los contenidos y la época de publicación.

\section{Dos perspectivas complementarias: Fosep Pla versus Ridruejo y Gómez de la Serna}

El primer grupo está basado en una triple disyuntiva: Pla-Ridruejo, Cataluña-Castilla y comienzos y finales de la colección, lo que nos permite analizar comparativamente las tres guías escritas por Josep Pla entre 19411961, es decir Costa Brava, Baleares y Cataluña, por un lado, y las dos de Castilla, Vieja y Nueva, de Dionisio Ridruejo y Gaspar Gómez de la Serna respectivamente, publicadas entre 1964 y 1974. Se trata de una oposición conceptual entre los dos autores más representativos de la colección y, tal vez también, de la misma editorial. Ambos respetuosos amigos y colaboradores en proyectos concretos, que personalizan admirablemente dos estilos de abordar la descripción geográfica y paisajística. Pero esta diferenciación esencial se superponen al de los contenidos también complementario o si se quiere, contradictorio: Castilla y Cataluña y a las fechas de publicación: 1943-1974, con el umbral en el cambio económico de mediados de la década de los sesenta.

17. Las "Guías de España" de Ediciones Destino contaron con un importante complemento gráfico, que constituye un excelente corpus de imágenes de la época debida a excelentes fotógrafos e ilustradores. Muchas de las fotos lo fueron de archivo, sobre todo las del Archivo Mas, pero otras fueron de encargo, siendo de destacar la labor de Ramón Dimas, fotógrafo deportivo de la revista, prematuramente desaparecido en 1965 y la de Francesc Català Roca (1922-1998), hijo del fotógrafo Pere Català Pic, que recibió varios premios a lo largo de su vida y realizó numerosas exposiciones. También fueron importantes las colaboraciones de Ramón Camprubí, para la Guía de Asturias y la del fotógrafo serbio Josip Ciganovic, nacido en Dalmacia en 1922 y afincado en Roma desde 1948, que en los años sesenta hizo varios reportajes fotográficos sobre distintas regiones españolas, por encargo del ministro Fraga, además del que le encargó Destino para su última guía, la de Aragón. 
En gran medida, Pla es un escritor de viajes, actividad que practicó asiduamente a lo largo de toda su vida. Pero sus escritos sobre viajes son más un pretexto para abordar las más diversas cuestiones de la vida cotidiana. Por eso, sus libros de viajes buscan la recreación de lo viajado y el pretexto para el encuentro consigo mismo en un permanente viaje interior. Así lo vio Ignasi Agustí, en el prólogo de un emblemático libro del escritor ampurdanés, La huida del tiempo (1945: 8): "iQué escalonamiento tan sutil y significativo el de sus libros hacia la más completa interiorización y unidad de su persona (...): primero sus Cartes de Lluny; a continuación, las Cartes meridionals. Más tarde Viatge a Catalunya, y después, Viaje en autobús. Al decir La huida del tiempo parece que llegue usted al término de un largo viaje hacia si mismo (...) Pero no es el tiempo el que huye, como no eran los paisajes los que viajaban. Es usted, es usted siempre". Por eso, en su guía, dice Pla en el prologo de su Costa Brava "está una parte de mi infancia y de mi adolescencia y muchos años de la edad madura (...) Yo soy un ciudadano del condado de Ampurias, sin conde y sin Ampurias, interesado en el Mediterráneo como ambiente del más eterno cosmopolitismo (...) Si este libro dio a conocer, más o menos, a mi país, puedo dar por bien empleado - creo- mis desvelos".

Y éste es el camino que, seguramente sin pretenderlo, inicia con su guías y transmite a la colección: "En el proceso de elaboración de una Guía turística se pueden seguir uno u otro de estos dos criterios: un criterio puramente mecánico, frío, estrecho, encaminado a dar con toda precisión los nombres de hoteles y restaurantes, detalles arqueológicos e históricos, planos (...), y otro más amplio, que sin perder de vista la necesidad de dar todas esas noticias (...) proyecte sobre el trabajo la experiencia personal (...) la sensibilidad del autor". La sensibilidad de Pla, a este respecto es un perfecto resumen del sentido literario y vivencial que deben tener, a su entender, este tipo de guías: "Una guía así supera la actividad de un solo hombre (...) debería construirse con la suma de conocimientos de toda procedencia, vastísima. Claro está que todas estas cosas convertirían a esta guía en un libro insulso y pedregoso, si no se tuviese el suficiente cuidado de airearlo todo con un poco de poesía, no sólo poesía lírica, sino de poesía culinaria, de recuerdos y de fantasías. Éste es exactamente mi elemento". Por eso mismo se siente halagado cuando esta forma de pensar y de actuar recibe el refrendo oficial: "El señor Calleja (...) alto funcionario de la Dirección General de Turismo, afirmó (...) 'el primer libro que se editaba en España en prosa auténticamente turística'” (Pla, 1948, págs. 7-9). 
En definitiva, Pla no va a ser sólo el creador de un estilo propio y personal de guía turística, como le dijo el tal señor Calleja, sino mucho más. Va a plasmar en sus tres guías una forma de hacer descripción geográfica íntima y casi existencial que, sólo tímidamente, permite vislumbrar un transfondo crítico que busque la explicación más que la recreación, mostrándose con ello en sintonía con la narrativa del momento. Así, lo dicen los propios editores de Destino en la sobrecubierta de la Guía de Cataluña: "Estamos ante el más certero y palpitante retrato de Cataluña publicado hasta hoy. Pla no podía - ni debía - limitarse a ser simple guía turístico, aunque su texto sea marcadamente práctico y orientador (...) una verdadera revelación para el lector que ve destruidas muchas falsas ideas y tiene acceso a una Cataluña tan auténtica como sorprendente". Tal vez a ese mismo estilo puede deberse el desconcertante título de su Guía de Mallorca, Menorca e Ibiza y ipor qué no de las Islas Baleares que es lo que correspondía? De cada isla por separado hace un introducción general, sobre su historia, arte, antigüedades, comarcas, gastronomía, etc., y es este lugar el tímidamente que aprovecha para alguna disquisición de mayor transcendencia social e histórica ${ }^{18}$.

En el otro extremo del tiempo y del espacio, las dos guías de Castilla, en tres volúmenes representan el otro polo de la colección. Sabemos, por declaración de los mismos protagonistas, que desde principios de los sesenta la editorial había formalizado ya el encargo a los dos autores, Ridruejo y Gómez de la Serna, para la redacción de las dos guías castellanas, Vieja y Nueva, respectivamente. Así se lo contaba Vergés a Delibes en carta de junio de 1964 (2002: 220): "Se trata del primer volumen de las dos Castillas, el que comprende toda Castilla la Nueva (...) escrito por Gaspar Gómez de la Serna (...) Castilla la Vieja, lo hará este verano otro ilustre apaleado oficial, nuestro amigo Dionisio Ridruejo". Pero, mientras la guía de Castilla la Nueva aparecía ese mismo año, la de Ridruejo tardaría todavía diez años más en salir, pues su autor se tomó el encargo con tal empeño y atención, además de coincidir con una etapa de su vida de intensa actividad política y social, que el resultado fue mucho mayor que el proyectado y no sólo en extensión material sino también en calidad de la descripción, lo que convierten a esta guía en una de las mejores obras en prosa de su autor.

Es el mismo Ridruejo quien nos facilita información de este proceso, en el prologo de su guía: "Se trata, claro es, de un libro de encargo que ha de

18. Como en el breve capítulo sobre la historia de Mallorca que se titula "De nación a provincia". 
encuadrarse en una serie editorial cuyas características conoce el lector: una Guía de España desarrollada por regiones cada una de las cuales había de caber en una volumen densamente ilustrado, lo que reduciría el texto, en le caso de mayor holgura, a tres centenares de folios" (1974: I.9). Es decir, la definición de lo que se quiso con esta colección y que se fue configurando

Figura 1. Ejemplos de fotos de paisajes eSPañoles. De arriba abajo y de izQuierda a derecha: Almería (Ramón Dimas), Castilla la Nueva (Francesc Catalá), los Monegros y los Pirineos (Josip Ciganovic)
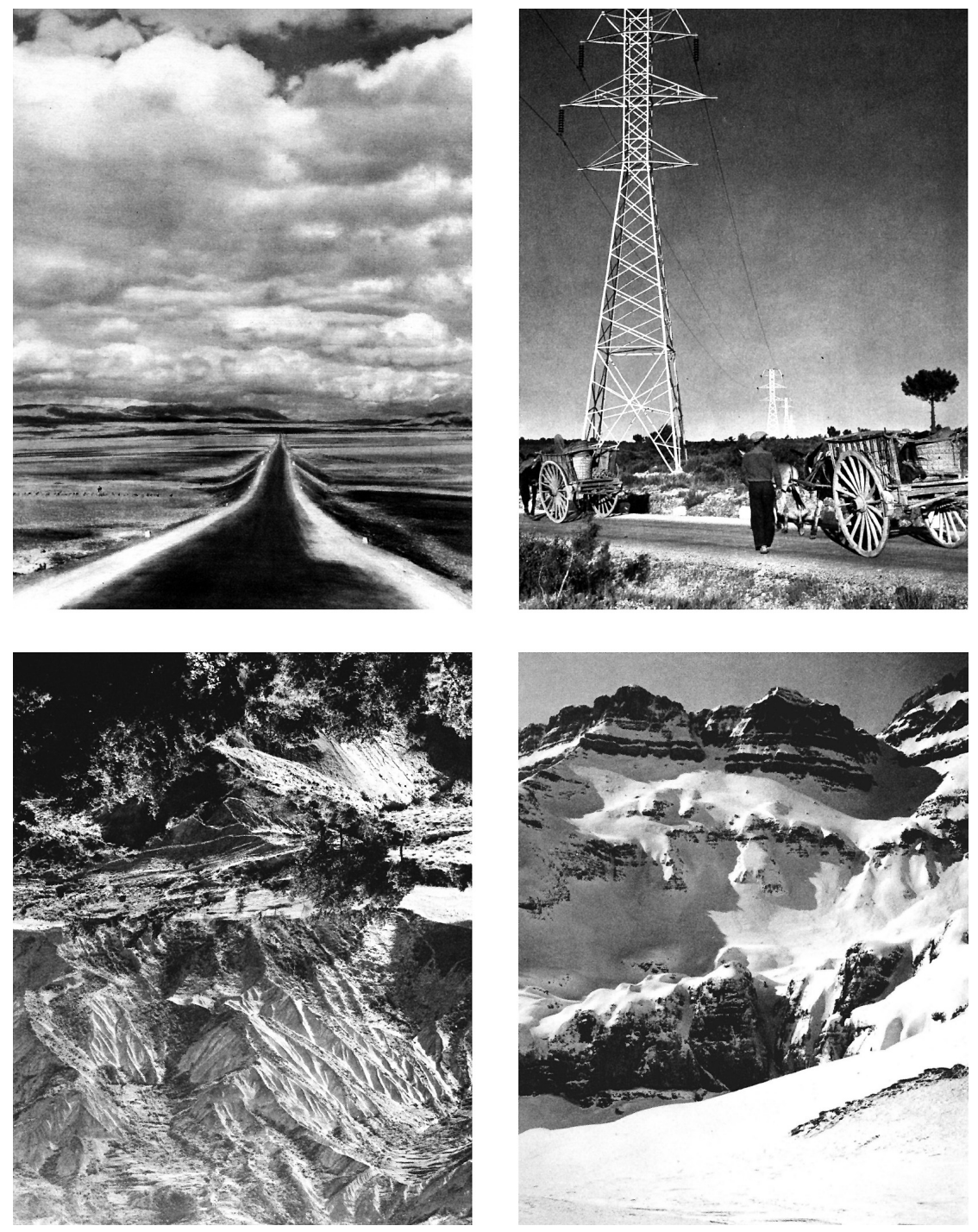
con el paso del tiempo y la edición de sucesivas guías. Pero a continuación va explicando sus dificultades para ajustarse al proyecto original, pues al terminar la provincia de Santander el manuscrito ya se aproximaba a los 300 folios, que al culminar la de Burgos superaba los 500. Por ello, a pesar de la generosidad de los editores que le habían concedido doble espacio (un segundo tomo), se imponía la reducción que inevitablemente dejaría la obra convertida en la sombra de una sombra.

En los diez años que mediaron entre el contrato y la culminación de la guía, Ridruejo se tomó el encargo con tal interés que pidió colaboración, no sólo a su secretario Fernando González Olivares, sino a amigos personales y cómplices políticos de extraordinaria valía, como Juan Benet o Fernando Chueca Goitia, con los que recorrió tierras y caminos castellanos (Gracia, 2007, pág. 383), en busca de información geográfica e inspiración intelectual muy superior al simple interés editorial.

La correspondencia del autor, recientemente publicada por Gracia García (2007), permite reconstruir las vicisitudes del proceso. Así, a finales de 1965, Ridruejo, en carta dirigida a Antonio Tovar, confiesa: "me he encerrado durante veinte días para terminar la Guía de Castilla, que hace seis meses que tenía que estar entregada, pero imagino que a mediados de enero pospondremos al trabajo para intentar hacer lo que se pueda" (Gracia, 2007, pág. 455). Se pudo poco, sin duda, pues un año después, el 25 de noviembre de 1966, escribe a su amigo Joan Teixidor, editor de Destino, dándole cuenta del estado de sus trabajos, le envía la guía de Santander, le avisa del envío de la de Burgos y le anuncia la próxima culminación de las de La Rioja y Soria. Pero lo más importante es que le expresa sus dudas sobre el proyecto original: "Como verás, la idea de hacer una guía propiamente dicha - utilizable - más bien que un libro personal y sintético, ha fracasado porque exige extensión desmedida". Es la disyuntiva latente a lo largo de toda la colección y que cada autor ha ido solucionando a su modo. Es también, si se quiere, la dualidad esencial de toda exposición geográfica: introspección o "extrospección", información, descripción o explicación, que Ridruejo tiene solucionada en su caso, pero sin olvidar que se trata de un libro de encargo: "Te ruego estudies bien el asunto ¿merece la pena refundir todo a 250 folios, renunciando a la guía propiamente dicha, o vale la pena ir a la guía útil desdoblándola en varios tomos? Lo dejo en vuestra mano. La refundición representa un cierto retraso. No mucho. Haré lo que convenga" (Gracia, 2007, pág. 460).

La solución la conocemos bien, fue la refundición en el libro personal, pero con el doble de la extensión proyectada. El resultado, la espléndida 
guía que conocemos, icono sin duda de la colección, junto con la de Baroja. El primer tomo (Santander, Burgos, Rioja) apareció en 1973, el segundo (Soria, Segovia y Ávila) en 1974. El 15 de abril de 1975 se presentaba la obra completa en la librería El Brocense, a cargo de Camilo José Cela. Un año antes, Ridruejo había recibido una carta de Ramón Carande felicitándole por la obra, a la que califica de "Libro epocal, ha de ser, o no sé lo que me digo. Guía al uso, no; están degeneradas por los autores, pensando, (los que piensen) en el usuario; libro imprescindible para quien quiera conocer de esas provincias todo lo que tienen y mucho de lo que tuvieron, de lo humano y de lo tectónico" (Gracia, 2007, pág. 528). De nuevo la contradicción aludida, la disyuntiva entre descripción o información, admirablemente expuesta en la breve nota epistolar del gran historiador de nuestra economía.

Pero no olvidemos que dicha disyuntiva ya había sido analizada por los propios autores. Unos años antes que Carande, Gaspar Gómez de la Serna, autor con amplia experiencia en los libros de viajes, afirmaba en su guía: "He creído que aquí debía limitarme a dos tareas muy claras y objetivas: informar al lector que va de viaje por Castilla la Nueva, para que sepa o recuerde dónde están las cosas que tienen un interés cualquiera y orientarle sobre cuál es el ángulo desde el que aquéllas aparecen en la plenitud de su sentido", lo que requiere la definición de un concepto tan geográfico como el de "región", que para Ridruejo: "Pertenece a la llamada Geografía física y por lo tanto resulta forzado cuando se le aplica a la Geografía histórica o política, cuyas unidades se han constituido casi siempre en un proceso de desarrollo espacial que excluye la obediencia a un "hábitat" homogéneo y determinante". Por eso, y como si

Figura 2. Junto al paisaje, el paisanaje. IzQuierda, la calle Sierpes, en Sevilla, según Ramón Dimas; Derecha, Campesinos de Aragón, SEGún Josip Ciganovic
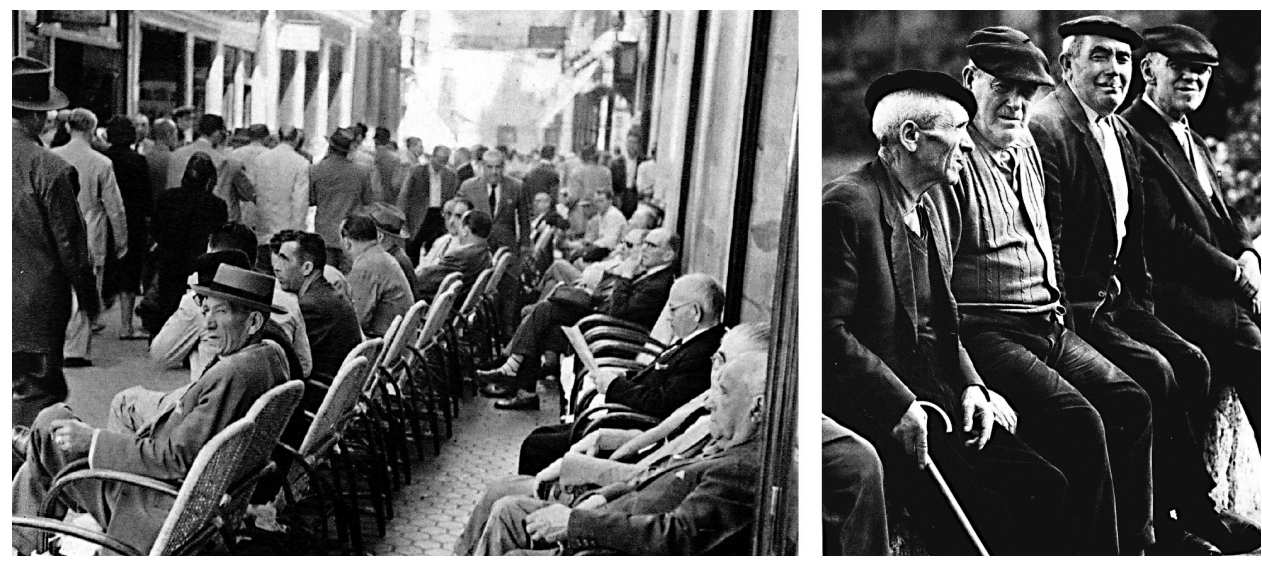
se hubieran puesto de acuerdo, para Gómez de la Serna: "Castilla la Nueva es una región histórica más que una región natural (...) Se trata de un paisaje que ha sido talado para campo de batalla (...) entre el sur islámico y el norte retraído en su prístina cristiandad, más que un bloque compacto como Castilla la Vieja, la Nueva ha sido un crisol en el que han convivido (...) distintos estilos de vivir".

\section{Dos guias urbanas: Carles Soldevila (Barcelona) y Fuan Antonio Cabezas (Madrid)}

Así pues, establecidos los límites conceptuales y territoriales de la colección, el resto de volúmenes se van a organizar según regiones, provincias y ciudades. Las guías propiamente urbanas van a ser dos: Barcelona y Madrid y, como en caso anterior, permiten apreciar con claridad las diferencias y similitudes de las dos grandes ciudades, así como las del estilo de sus dos autores.

La Guía de Barcelona, tercera de las publicadas tras la Costa Brava y las Baleares, era la consecuencia lógica de una colección que, al principio, parecía tener dos objetivos claros: Cataluña y el turismo. Pero la guía de una gran ciudad, sobre todo si se trata de Barcelona y se encarga a un autor como Soldevila en plena crisis de la posguerra, tenía que superar esos estrechos límites. Para Soldevila, conocer una ciudad "consiste en penetrarse de su atmósfera espiritual, en desposarse con su presente, su pasado y su futuro, en tomar cariño a sus cualidades y sentir el sabor agridulce de sus grandes defectos". Y todas estas categorías, en la pluma de este escritor, en un momento crítico de su vida y de su obra, se van a convertir en un producto muy superior al de un simple guía turística. "Mi deseo (...) es la de procurar a los barceloneses, casi más que a los forasteros, un estímulo para adentrarse en el alma de la ciudad." Dice el autor en su prólogo, dejando bien a las claras cual es el objeto y quiénes son los destinatarios de su guía. Y esa alma de la Barcelona de finales de los años cuarenta del pasado siglo contiene ingredientes que trascienden la mera objetividad geográfica, para proyectar la crisis de una sociedad y la desazón del propio autor.

A lo largo de su obra, Soldevila fue un escritor polifacético con un denominador común: su atención a Barcelona y a lo barcelonés, como síntesis y principio a la vez de Cataluña y lo catalán, actitud que tan bien se refleja en los términos de cap i casal. Pues bien, si Barcelona es cap i casal de Cataluña, las virtudes de la ciudad deben irradiar sobre el país, pero sus defectos son exponentes también de las incongruencias y vicisitudes de la 
historia de éste, lo que se siente con especial preocupación tras el desastre de la Guerra Civil. Pero, entre una y otro, hay motivo para la esperanza: "Lo notable (...) es que, abandonada a impulsos sueltos y a iniciativas de virreyes y capitanes generales que no solían durar en sus cargos (...) haya llegado Barcelona a ser lo que es y tenga el porte que tiene". Más adelante, al analizar la ciudad desde la altura, afirma: "Como ocurrió que la colonia modesta y provincial se alzase con la capitalidad (...) entre el Llobregat y los Pirineos y más tarde de toda Cataluña y luego de todo el reino catalanoaragonesa. Y por qué de capital de un reino pasó a la de un principado y vio como la Valencia del siglo XV eclipsaba su comercio y sus industrias (...) ¿Por qué la nave barcelonesa había de capear tan penosamente los temporales del Renacimiento y del Absolutismo?", y así continúa enumerando las vicisitudes de la historia de Cataluña desde la óptica de la ciudad, sin duda porque ésta era la única forma en la época de expresar esas inquietudes sin levantar reservas en el poder.

De esta forma, Soldevila reafirma de nuevo en esta guía su decisión, que ya apuntara en obras anteriores, de colaborar con la "moda meritísima que de unos años a esta parte se esfuerza por salvar el recuerdo de una Barcelona condenada a inminente y definitivo naufragio" (Soldevila, 1945, pág. 4). Es lo que pretende al "escribir esta guía que, en m ilusionado deseo, debería contribuir tanto a aumentar el cariño a la ciudad de hoy como a mejorar las coyunturas de la ciudad del mañana" (Soldevila, 1951, pág. 9).

El caso de Madrid es necesariamente distinto. Sin perjuicio de las evidentes similitudes entre dos grandes ciudades próximas, en el mismo país y de parecido tamaño y funcionalidad, la clásica controversia Barcelona-Madrid cobra toda su especial relevancia cuando se la analiza desde una perspectiva personal y transcendente como es el caso de estas guías. La publicación de la Guía de Madrid de Juan Antonio Cabezas, en 1954, significó un reto para la editorial catalana. Era el quinto volumen de la colección, doblemente necesario para la coherencia de ésta desde que se había publicado la Guía Barcelona y la del País Vasco de Baroja, lo que suponía pasar del nivel de catalán y tierras próximas al de toda España. Pero, existieron también razones más concretas, de índole editorial, como dejó constancia el mismo Vergés, en carta dirigida a Delibes (2002, pág. 114): "Mi viaje [a Madrid] ha estado supeditado a la terminación del libro Madrid, que finalmente se halla ya encuadernado. Yo voy a la capital a poner esa guía a la venta, ya que es una obra que nos ha costado un gran esfuerzo y es preciso salir a la plaza personalmente a vigilar el toro (...) que en este caso no sé si son los libreros o los futuros compradores".

Para la "lidia de ese toro" se había escogido a un prestigioso periodista, buen escritor y conocido cronista de Madrid, que eligió para este empeño un 
estilo inspirado en los numerosos antecesores que le habían precedido en el relato y la descripción de esta villa, considerada por unos como rompeolas de las Españas desde el XVII y para otros como causa también de su decadencia y desvertebración (Ringrose). Al igual que Soldevila que pretendía adentrarse en el alma de la ciudad, también Cabezas utiliza la misma figura para el caso de Madrid: "Algo más profundo, sutil e inefable: esa alma total de Madrid - de los Madriles - que vive en sus estratos de tiempo, arquitectura y demografía". Pero a diferencia de lo visto por aquél para Barcelona, cabeza de una nación irredenta que era preciso recuperar, Madrid es la capital por antonomasia: primero de un Imperio, luego de la Corona, de la Nación por último. Capitalidad que los madrileños sobrellevan algo a su pesar, a desgana de sus propios intereses si es que pueden diferenciarse los unos de los otros. Es la tópica distinción entre corte y villa, pues precisamente por ser ambas cosas, Madrid va ser una ciudad alegre y cosmopolita en la que nadie es extraño y que debe su personalidad precisamente a lo foráneo y a los forasteros. Es lo que Cabezas Ilama, al final de su libro: "Madrid, crisol de paletos", entendiendo por paletos, sin tinte peyorativo, todo aquel habitante de la ciudad no nacido en ella, entre los que cita una amplia nómina de ilustres madrileños desde Felipe II a Galdós o Arniches y en la que cabría incluir al mismo autor, asturiano de nacimiento y, sin dejar de serlo, madrileño "de oficio". Por eso, "Madrid esta lleno de nostalgias. Cada patio de vecinos se convierte por las mañanas en una especie de altavoz que transmite ondas folklóricas con calor humano": alalás gallegos, cante hondo andaluz, jota aragonesa, etc., cada patio de vecinos como expresión a menor escala, en definitiva, del crisol de la misma ciudad.

\section{El País Vasco de Baroja y la Andalucía de Pemán}

Por la personalidad literaria de los autores y la geográfica de ambas regiones, estas dos guías constituyeron dos referentes esenciales en la colección que analizamos. La Guía del País Vasco, publicada en 1953, fue el cuarto volumen de la colección, y fue acogida con gran interés por la prensa especializada del momento ${ }^{19}$. La de Andalucía de José Mª. Pemán, lo fue cinco años después, cuando tras la aparición de las de Madrid y Galicia, la colección estaba ya plenamente consolidada y, en opinión de los editores: "La incorporación de un volumen sobre Andalucía (...) era de todo punto necesaria".

19. Como lo demuestra los "recortes de glosas aparecidas en el Norte de Castilla sobre el País Vasco de Baroja" que Delibes remitió a Vergés en aquel mismo año (2002, pág. 108). 
Pero ambas constituyen dos aportaciones esenciales a la geografía literaria de nuestro país. Las dos fueron libros de encargo, como se subrayan sus autores en los prólogos respectivos: "Me encargan escriba un libro sobre el País Vasco. Un poco tarde es para mí" (1953, pág. 9), son las palabras con las que Baroja empieza su guía, de forma parecida a como lo hace Pemán con la suya. "Cuando Ediciones Destino solicitó de mí que escribiera una Guía de Andalucía, mi primer impulso fue el de rehuir la tarea y casi protestar del encargo" (1958, pág. 9). Pero las razones de la reserva van a ser distintas: la edad en el caso de Baroja, el poco espacio en el de Andalucía, lo que va a determinar un enfoque diferente de ambas obras, aunque con notables resultados en ambos casos.

Figura 3. El COSTUMBRISMO SIEMPRE PRESENTE: ARRIBA IZQUIERDA: TOROS EN BELMONTE de Francesc Catalá; arriba derecha: botas de vino en Pola de Siero de Ramón CAMPRUBí; DERECHA: BOtIJOS ARAGONESES DE JOSIP CigANOVIC
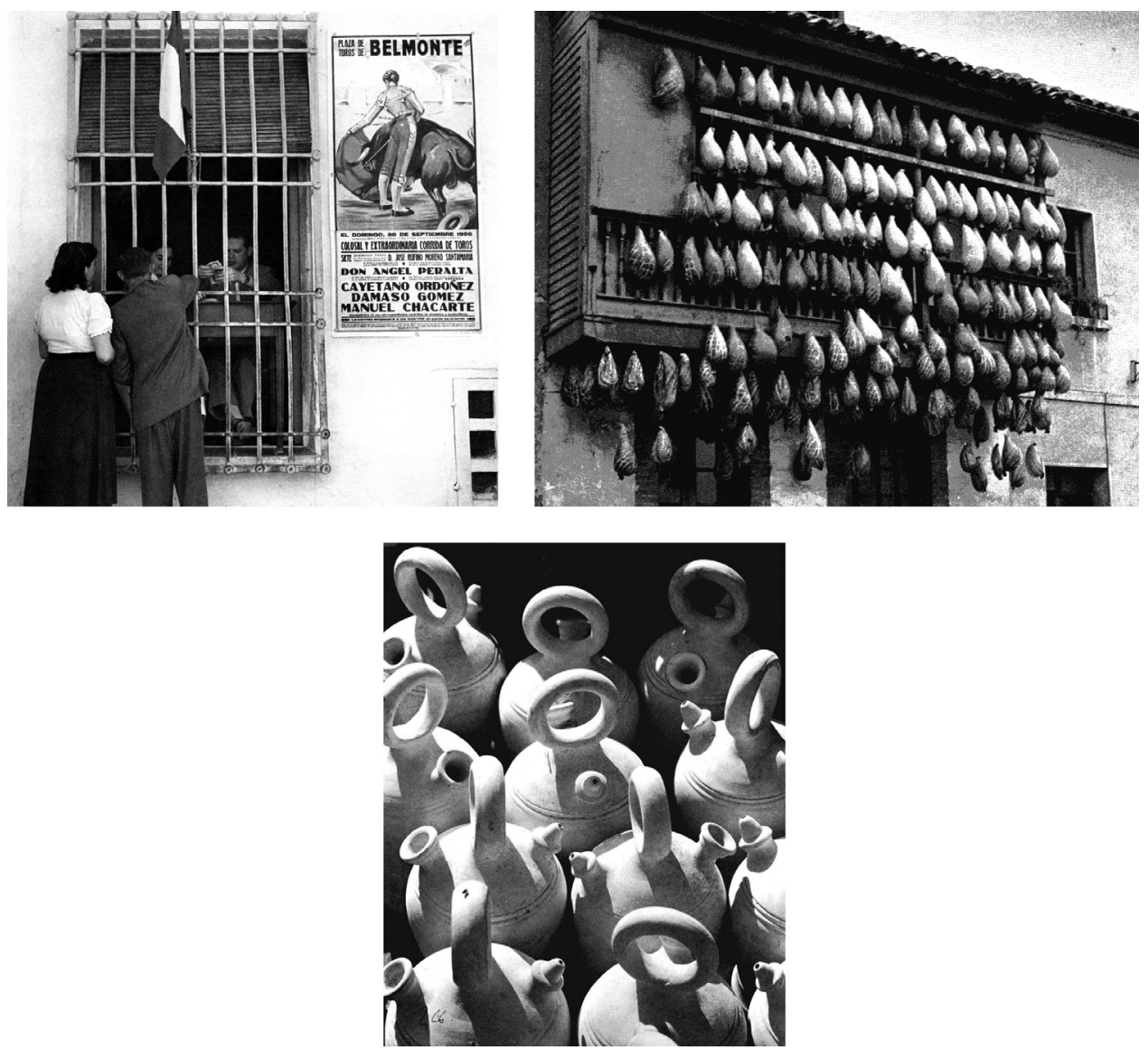
Como es sabido, Baroja fue un gran viajero, aficionado también a los libros de viajes, que eran para él fuente de experiencias personales. Viajes frecuentemente compartidas con sus hermanos, Carmen y Ricardo, o con otros amigos, desde Maeztu a Ortega y Azorín, o con el también novelista Ciro Bayo o el polémico suizo Paul Schmitz. Experiencias que frecuentemente reflejaba en sus novelas. Pero cuando le llega el encargo de Destino es ya un hombre viejo, incapacitado para recorrer, otra vez más, los parajes de su tierra. "He perdido mis condiciones ambulativas y me he transformado en un hombre completamente sedentario (...) No sé si esto se podrá considerar como una guía con exactitud completa y con cierto rigor científico. Supongo que no, pero yo no puedo hacer otra cosa (...) Yo no he podido escribir este libro con un criterio de historiador o de geógrafo; no he tenido más remedio que hacerlo como lo puede hacer un escritor viejo y curioso, que se vale de sus antiguos recuerdos, aunque estos sean confusos y poco detallados" (1953, pág. 10).

Fiado en sus recuerdos, Baroja redacta unas particulares "memorias", con formato de guía geográfica y con su particular personalidad literaria como ingrediente. Su País Vasco comprende las tres provincias vascongadas, más Navarra y las tres provincias vascas al norte de los Pirineos, lo cual, para 1953, era una importante toma de postura.

La conocida técnica narrativa de Baroja, realista, basada en la observación de ambientes y situaciones de la vida real, con pinceladas de carácter impresionista, se ajusta admirablemente a las necesidades de una guía geográfica. Por eso, en ocasiones las descripciones paisajísticas adquieren perfiles magistrales, pero otras veces se diluyen en el mundo de los sentimientos personales del autor: "No comprendo por qué razones me sentí desde joven vasquista. No fue por contagio familiar (...) Mis hermanos se encontraban a gusto en Valencia. Yo no. El sol fuerte y las casas encaladas no eran lo mío, no me gustaban. Cuando fui desde Valencia a Cestona a ejercer de médico, comprendí que el clima vasco era mi clima, por lo menos mi clima de aldea". Lo mismo ocurre con la permanente contradicción barojiana, como cuando se refiere a la lengua, tema nada fácil de tratar en aquellos años: "Advierto que cuando pongo alguna palabra o alguna frase en vascuence ni empleo la ortografía moderna, porque me parece una ridiculez en una lengua vieja y moribunda cambiar los signos ortográficos y hacerlos incomprensibles para el hombre corriente (...) Hace años en la radio Valladolid el speaker dijo refiriéndose al vascuance: 'Quién se atreverá a ladrar en ese dialectucho'. La frase es completamente absurda. ¡Qué pedantería más huera! ¡Como si esto nos importara a los 
nacidos en el País Vasco! (...)] Esto del orgullo por la lengua que se habla me parece una pobre tontería".

La guía se articula en lo que podríamos Ilamar itinerarios sentimentales o del recuerdo. Por tierras de Álava, Guipuzcoa, Vizcaya y Navarra es la primera parte; de nuevo, Por tierras de Guipuzcoa y Navarra, la segunda; la tercera, El País Vasco francés, y en las dos últimas, abandona la dimensión territorial y paisajística, para incorporar un conjunto de experiencias, sentimientos y recuerdos, con los que pretende expresar su personal y magistral visión del país y sus gentes: Marinos, Poetas, Músicos y Artistas, cuarta parte y Antiguas leyendas y supersticiones, la quinta. Pero sus recuerdos y esas mismas creencias y valores le llevan, a veces, a posturas discutibles, incomprensibles desde el simple punto de vista geográfico, como recordará Josep Vergés años después, en una entrevista en La Vanguardia: "Escribió un libro de viajes sobre el País Vasco sin una línea de Bilbao. No me atrevía a publicar el libro así y él exclamaba: 'Si Bilbao no tiene ningún interés'. Al final su sobrino Caro escribió unas líneas". De todas maneras, y a pesar de la colaboración de su prestigioso sobrino, la descripción de Bilbao en su guía es mínima, sin duda como consecuencia del "escaso interés" que Baroja atribuía a la ciudad.

El caso de Pemán es diferente. Sus reservas del principio se deben a la imposibilidad de escribir una guía de Andalucía en el mismo espacio en el que Pla lo había hecho para la Costa Brava, o el dedicado a Madrid y Barcelona. "Se me tranquilizó, o se me sobornó, para decidirme a aceptar el encargo, asegurándome que lo que se quería era más que una exhaustiva catalogación, una entrañable y personal visión de mi tierra y región andaluza" (1958, pág. 9), lo que le permite distanciarse hábilmente de la guías de viajero de carácter informativo: "Que nadie me haga, pues, reclamaciones a nombre de las exactitudes del 'Baedeker' o de las soseras de la 'Michelín'".

Fiel a su estilo y posición, la visión que Pemán tiene de su tierra es diametralmente opuesta a la que Baroja tiene de la suya: "Andalucía es como una enorme e ilustre familia cuyos segundos apellidos, a fuerza de enlaces y trasiegos de sangre, han variado infinitamente (...) un poco traviesa fue la vieja Bética. Abrió muchas puertas, recibió muchas visitas; se cogió de muchos brazos galantes (...) Andalucía es por esencia insolidaria, individualista y localista (...) Ya comprenderás lector lo peligroso que es hablar de una región en la que cada habitante querría inconfesadamente que se hablara de él" (Pemán, 1958, pág. 11).

Como ello no es posible, Pemán va a estructurar la descripción de su tierra en varios itinerarios básicos que, partiendo de Sevilla, permiten a un 
presunto viajero, que a veces se parece más a un romero, percibir y sentir, más que recorrer, la tierra andaluza. Porque, más allá del tópico, si la guía de Baroja es, en cierta medida, un libro de memorias, los viajes de Pemán tienen mucho de romería andaluza, vistosa, risueña, amable e imaginativa. "El que tenga prisa por llegar a Sevilla no debe escoger esta vía marítimo-fluvial [se refiere al Guadalquivir] Desde Cádiz a Sevilla se tarda tres horas en automóvil; cuatro en tren 'expreso' y doce en barco. Claro está, pues, se debe ir en barco" (Peman, 1958, pág. 23). O mejor aún, cuando describe El Rocío: "La carreta que entierra sus ejes en el arenal y la mula que ha caído enredada en su propio atalaje son ocasión para probar el esfuerzo y el buen humor (...) El Rocío ha conocido muchas bromas, pero ninguna bronca (...) se grita 'viva la Blanca Paloma' y se bebe un buche de fino" (Pemán, 1958, pág. 103).

\section{Dos regiones atlánticas y otras dos mediterráneas}

Intercalados cronológicamente entre las guías mencionadas, se fueron publicando otras cuatro, de estructura básicamente regional y localización periférica. Fueron éstas: Galicia de Carlos Martínez. Barbeito (1957), El País Valenciano de Joan Fuster (1962), Asturias de Dolores Medio (1971) y Murcia de José Vicente Mateo (1971). Dos regiones a orillas del Mediterráneo, las otras dos plenamente atlánticas. Algunos de éstos autores ya eran prestigiosos escritores cuando escribieron estas guías, otros casi desconocidos, pero el denominador común de las cuatro es el equilibrio que en todas se mantienen entre la descripción geográfica del fondo y la creación literaria de la forma.

Respecto a la descripción de fondo, existe una evidente similitud entre la Galicia, de Martínez Barbeito, y la Asturias, de Dolores Medio y, si se quiere, con el resto de la cornisa cantábrica: tierra, clima, vegetación, proximidad, etc. Así, ambos autores, subrayan el efecto que al presunto viajero le produce Ilegar a estas tierras desde la árida meseta: "Quien penetra en Galicia por vía terrestre y procediendo de Castilla, en seguida advierte la diferencia entre lo que acaba de dejar y lo que empieza a ver", dice Barbeito al principio de su guía (1957, pág. 9), con palabras que casi repite Dolores Medio años después: "Asturias ha sido siempre la gran sorpresa para el viajero que llega a ella procedente de Castilla (...) El paisaje castellano, ancho y caliente, se sustituye, casi sin transición, por un paraje abrupto de un verde brillante y húmedo" (1971, pág. 9). Pero a partir de aquí, las diferencias de estilo y de forma literaria confieren personalidad propia a cada guía. La Galicia de Martínez Barbeito se inicia con una introducción general sobre 
los caracteres más representativos del país, que constituye un excelente ensayo sobre el ser profundo y la personalidad geográfica e histórica del mismo. Así, descompone en primer término los elementos de ese paisaje visual y espiritual: las manchas o contrastes de vegetación, las torres, aldeas, aguas y vientos, mar, luz, niebla, etc., pero también la emigración, el contraste entre arcaísmo y modernidad, el matriarcado, la lengua, la cocina, y un largo etcétera de factores con los que trasmite la peculiaridad de una tierra a través de los sentimientos del autor. El resto del volumen se estructura en los consabidos itinerarios que permiten al lector-viajero adentrarse en los paisajes del país, pero que el autor diferencia en dos niveles: itinerarios generales y circuitos especiales, lo que le permiten una agilidad en la descripción muy adaptada a la riqueza de contrastes de la tierra.

Similar en algunos aspectos y muy diferente en otros es la descripción que de Asturias hizo Dolores Medio. La guía no contiene una introducción, como la de Barbeito, a modo de reflexión general sobre el país. La descripción comienza en Oviedo, que centraliza y resumen los caracteres de la región. Junto a la capital, los otros dos núcleos urbanos más significativos: Gijón y Avilés, vistos los cual, se adentra directamente, con excelente prosa, en los paisajes, itinerarios y valles del país: la costa, los Picos de Europa, el Nalón, los Oscos, el occidente, los pantanos, etc.

Entre la publicación de ambas guías, la editorial Destino había encargado a Joan Fuster la redacción de la del País Valenciano, un libro que iba a ser muy representativo en la bibliografía de su autor, publicado el mismo año que viera la luz Nosaltres els valencians, su obra más conocida y uno de los hitos esenciales en la configuración del nacionalismo valenciano. La guía de Fuster cuenta con una introducción de 114 páginas, casi una tercera parte del libro, en la que analiza la tierra, la historia, la gente, la vida, la riqueza y, en definitiva, el modo de ser valenciano. Con una excelente prosa, Fuster va desgranando una serie de argumentos que le permiten definir ese modo de ser. Primero, la superación del tópico del levante feliz, del jardín de flores: "El País Valenciano no se agota en este cliché ubérrimo y relamido. Desde Morella a Orihuela, su paisaje, en aspecto y en providencia, cambia, se contradice y diversifica sin cesar" (1962, pág. 10). Segundo, para Fuster, Valencia es tierra de convergencia y confluencias, de transición con las vecinas que se aglutinan en un espacio con personalidad propia: "Elche con sus palmeras arriesgadas, Morella, gótica y adusta, y la Sueca del húmedo arrozal (...) parece que no hay nada en común (...) El contraste no tiene siquiera ese atenuante [la lengua] cuando se trata de una Orihuela casi murciana, de un Segorbe casi aragonés, de una Ayora casi castellana. Y, sin 
embargo, la unidad existe $o$, si se quiere, mejor que unidad, personalidad" (1962, pág. 12). Tercero, lo valenciano como forma peculiar de la cultura catalana, enraizada con la misma de la que forma parte indisoluble. Es la dimensión más problemática de su discurso, la que en su momento creó múltiples discusiones y polémicas, cuyo eco llega hasta nuestros días, pues ello le lleva a adoptar una cierta displicencia respecto a algunos componentes propios de este pueblo, con raíces diferentes a las del Principado: "No hará falta recorramos muchos kilómetros, para darnos cuenta del fuerte cambio material y sociológico que se ha producido al traspasar la frontera lingüística. Si ya es bastante notorio en la fisonomía de los cultivos, lo resulta mucho más en el carácter y en la vida de los hombres. El fenómeno se repite cuantas veces, en el País Valenciano, se cruza la línea divisoria de las lenguas (...) Los valencianos catalanoparlantes llamamos xurros a los aragoneses y, por extensión, a la gente de su mismos linaje y lenguaje: el mote, despectivo o no, subraya aquella diferencia de hecho con un tenue acento de despego" (1962, pág. 210).

Similar planteamiento respecto al tópico del feliz jardín mediterráneo es el que sostiene Mateo respecto a Murcia. La guía comprende, en realidad, el antiguo reino de este nombre, es decir las actuales provincias de Murcia y Albacete, de muy diferente y contrastado paisaje, que el autor resume en la oposición Huerta-Mancha, que desgrana a lo largo de más de 120 páginas de introducción, con temas como la tierra, la historia, riqueza, los hombres, la vida, etcétera, temas todos ellos en los que se aprecia la influencia de otras guías anteriores.

\section{Final: Canarias y Aragón, ¿una colección inacabada?}

La colección se completa con las guías de las islas Canarias y Aragón. Al final, dieciséis guías que comprenden toda España, excepto Extremadura y León, organizadas de forma aparentemente arbitraria, que no es tal si nos atenemos a las vicisitudes y al estilo editorial al que ya nos hemos referido. Estas guías agrupan el territorio español con diversas escalas y criterios: las dos ciudades más importantes (Madrid y Barcelona); una comarca (la Costa Brava), dos actuales regiones-provincias (Baleares y Asturias), dos provincias (Santa Cruz Tenerife y Las Palmas de Gran Canaria); tres regiones históricas (las dos Castillas y el antiguo "reino" de Murcia); y otras cuatro regiones históricas coincidentes con las actuales divisiones autonómicas (Cataluña, Aragón, Galicia y Valencia). Es evidente que ello es consecuencia de las vicisitudes empíricas y de las necesidades editoriales del proyecto, 
pero también lo es de un cierto criterio geográfico y regionalizador, que pretendió huir de la cómoda división provincial y buscar otro enfoque más en sintonía con el fin de la colección.

Las Islas Canarias fue el único territorio español en el que, de hecho, se respetó la estructura provincial. Pero no de forma explícita, ya que en el nombre de cada guía sólo se especifica en nombre de las islas que las componen, cuyo estudio se encargó además a dos autores de personalidad literaria muy distinta. A la vista de ello cabría preguntarse la razón de este cambio de criterio editorial que, para aquel entonces tenía un perfil bien definido. La guía de Claudio de la Torre 20 es esencialmente una guía de Gran Canaria, con unos complementos mucho más breves referidos a las otras dos islas orientales del archipiélago y una también breve introducción sobre la historia, el mito y las leyendas de estas famosas islas atlánticas. El autor tiene profundas raíces en las islas, sobre todo en Gran Canaria ${ }^{21}$ y, en cuanto excelente escritor, fue capaz de realizar un magnífico ensayo literario sobre esta isla con un alto valor geográfico y turístico. Pero no sabemos hasta que punto la idea de un segundo tomo, siguiendo el mismo modelo, con las cuatro islas restantes sería de su agrado e interés. Seguramente por ello, la editorial prefirió encargar ese tarea a otro autor, Alfredo Reyes Darias ${ }^{22}$, que publicó su guía tres años después, con una estructura diferente: un prologo mucho más extenso, en la que el autor describe las categorías propias de lo canario, a su juicio: mitos, arte, guanches, costumbres, música, danzas, fiestas, romerías, cocina. etc. y una pura descripción, muy pegada a lo concreto de las cuatro islas occidentales.

Por último, la guía de Aragón, de Santiago Lorén, fue publicada en 1977, cuando las circunstancias sociales y políticas del país experimentaban una rápida transformación y cuando ni la editorial ni el público al que iba destinado este tipo de lecturas era ya el mismo. Pero no por ello podemos desmerecer su trascendencia, dada la importancia de la región de que se trata y el excelente trabajo de su autor. Es evidente que, a los dos años de la muerte de Franco y con las primeras elecciones celebradas en democracia, las circunstancias eran otras. Lo eran ya de la misma editorial, como veíamos más arriba, y lo era también la configuración geográfica y autonómica del país, como lo afirman en la contraportada los mismos responsables de la edición: "En el tiempo en que se dirime la apasionante cuestión de las

20. Gran Canaria, Fuerteventura y Lanzarote. Canarias Orientales.

21. Su abuelo, Néstor de la Torre, planificó la construcción del Puerto de la Luz.

22. Tenerife, La Palma, Gomera, El Hierro. Canarias Occidentales. 
autonomías regionales, es posible que este libro sea un alegato más para reconocerlas y promocionarlas". Y aunque ello no fuera así, al menos no parece que lo fuera en la voluntad del escritor, lo cierto es que Aragón es una pieza clave para entender este mosaico inacabado en permanente transformación que parece España. "A un espíritu cartesiano sistemático de la duda se le puede plantear la cuestión de si Aragón existe" (Lorén, 1977, pág. 9). La misma pregunta que, respecto a España, venían haciéndose los espíritus más sensibles de este país desde hacía más de cien años.

Recibido 01.09.08

Aceptado 07.11.08

\section{BIBLIOGRAFÍA}

Arroyo, F. (2007): "Josep Pla y las Guías de España de Ediciones Destino. Una perspectiva geoturística y literaria de España a mediados del siglo XX", en Paül, V. y Tort, J. (eds.), Territorios, paisajes y lugares, Galeradas y AGE, Barcelona, pp. 389-404.

Baroja, P. (1953): El País Vasco, Destino, Barcelona, 520 pp.

Cabezas, J. A. (1954): Madrid, Destino, Barcelona, 562 pp.

Catalá-Roca, F. (1995): Imprssions d'un fotògraf. Memòries, Edicions 62, Barcelona, 204 pp. Delibes, M. y Verges, J. (2002): Correspondencia (1948-1986), Destino, Barcelona, 472 pp. Fuster, J. (1962): El País Valenciano, Destino, Barcelona, 528 pp.

Geli, C. y Huertas Clavería, J. Ma (1991): Las tres vidas de Destino, Anagrama, Barcelona, $234 \mathrm{pp}$.

Gómez de la Serna, G. (1964): Castilla La Nueva, Destino, Barcelona, 596 pp.

Gracia, J. (2007): El valor de la disidencia. Epistolario inédito de Dionisio Ridruejo. 19331975, Planeta, Barcelona, 588 pp.

Kessler, M. (1996): El paisaje y su sombra, Ed. Universitaria, Barcelona, 376 pp.

Lorén, S. (1977): Aragón, Ed. Destino, Barcelona, 604 pp.

Manjón-Cabeza Cruz, D. (2008): "Poesía de posguerra en Barcelona", Revista de Literatura, 70, 139, pp. 141-163.

Martínez Barbeito, C. (1957): Galicia, Ed. Destino, Barcelona, 526 pp.

Mateo, J. V. (1971): Murcia, Ed. Destino, Barcelona, 547 pp.

Medio, D. (1971): Asturias, Ed. Destino, Barcelona, 614 pp.

Moret, X. (2002): Tiempo de editores, Ed. Destino, Barcelona, 400 pp.

Pemán, J. Ma (1958): Andalucía, Ed. Destino, Barcelona, 572 pp.

Pla, J. (1942): Viaje en autobús, Ed. Destino, Barcelona, 286 pp.

Pla, J (1945): La huida del tiempo, Ed. Destino, Barcelona, 342 pp.

Pla, J. (1948): Guía de la Costa Brava, Ed. Destino, Barcelona, 436 pp.

Pla, J. (1950): Mallorca, Menorca e Ibiza, Ed. Destino, Barcelona, 582 pp.

Pla, J. (1961): Cataluña, Ed. Destino, Barcelona, 632 pp.

Reyes Darias, A. (1969): Tenerife, La Palma, La Gomera, El Hierro, Ed. Destino, Barcelona, 614 pp.

Ridruejo, D. (1974): Castilla La Vieja, vol. 1, 686 pp.; vol. 2, 608 pp., Ed. Destino, Barcelona.

Ridruejo, D. (1976): Casi unas memorias con fuego y con raíces 1912-1975, Planeta, Barcelona, $487 \mathrm{pp}$. 
Serrano, Ma del M. (1993): Las guías urbanas y los libros de viaje en la España del siglo XIX, Publicaciones de la Universitat de Barcelona, Barcelona, $386 \mathrm{pp}$.

Soldevila, C. (1945): Historias barcelonesas, Delfos, Barcelona, 230 pp.

Soldevila, C. (1951): Barcelona, Ed. Destino, Barcelona, 450 pp.

Torre, C. de la (1966): Gran Canaria, Fuerteventura y Lanzarote, Ed. Destino, Barcelona, 540 pp.

\title{
Resumen
}

La editorial catalana Destino publicó, entre 1943 y 1977 una colección de dieciséis guías de diversas regiones y ciudades de España que comprenden la práctica totalidad del país y constituyen un importante legado editorial, literario y geográfico de la época. Este tipo de publicaciones, intermedias entre los libros de viaje y las guías turísticas propiamente dichas, no cuentan con la atención que merecen, dada la calidad de su edición, con un importante acompañamiento gráfico y la notable importancia de la mayoría de los autores (Pla, Baroja, Pemán, Ridruejo, Fuster, Martinez Barbeito, Dolores Medio, etc.). Además, el tiempo de su publicación, casi coincidente con el que duró el franquismo, convierte a esta colección en un documento de indudable valor para le Geografía cultural

Palabras clave: España; guías turísticas; geografía cultural; geografía y literatura.

\begin{abstract}
The Catalonian publishing company Destino published a collection of sixteen guides about different regions and cities of Spain.

These guides almost covered the whole country and are an important publishing and geographic legacy of the time.

This type of publications, somewhere between travel books and tourist guides, has not received the praise they deserve.

The quality of the edition, the graphic material and the high standard of most of the authors (Pla, Baroja, Pemán, Ridruejo, Fuster, Martínez Barbeito, Dolores Medio and others) are remarkable.

Furthermore, these guides were published under General Franco's regime, a circumstance that has rendered them a very valuable set of documents of cultural Geography.
\end{abstract}

Key words: Spain; tourist guides; cultural geography; geography and literature. 